\title{
Open Science in Applied Linguistics: A Preliminary Survey
}

\section{Introduction}

The first official step toward Open Science (OS) in Applied Linguistics (AL) was arguably the establishment of IRIS, a discipline-specific data and instrument repository, back in 2011 (Marsden et al., 2016). Since then, there have been active efforts to improve methodological rigour and research quality (e.g., Gass et al., 2021; Plonsky, 2014; Plonsky et al., 2020), as well as initiatives to enhance research transparency, reproducibility and accessibility, such as Registered Reports at Language Learning (Marsden, Morgan-Short, et al., 2018) and the Open Accessible Summaries in Language Studies (OASIS) initiative (Marsden, Alferink, et al., 2018).

Despite these efforts, however, a recent survey (Isbell et al., 2022) on applied linguists with regards to scientific misconduct and questionable research practices (QRPs) painted a lessthan-rosy picture: Of the 351 respondents, 94\% admitted to at least one form of QRPs in quantitative research. While there have been surveys indicating a general recognition of the value and relevance of OS (cited in Marsden, 2019) and specific OS practices such as replication (McManus, 2021) to the AL community, the high prevalence of QRPs reported in the recent survey (Isbell et al., 2022) indicates a misalignment between the attitude to and the adoption of OS practices. This points to a knowledge gap regarding what prevents applied linguists from engaging in OS practices despite the recognition of their value. We seek to address this gap by surveying applied linguists not only on their OS attitudes and practices, but also on the perceived barriers to OS practices.

\section{A Preliminary Survey}

The survey was administered through Google Forms. It was advertised via the second authors' contacts and further disseminated by them, as well as advertised on Twitter and Facebook. The survey ran for a period of four weeks (from February to March 2021) and received 157 responses in total from applied linguists of across different career stages.

Before we present the results of this exploratory study, it is important to emphasise the preliminary nature of the survey and the likelihood of self-selection bias. We do not claim that the sample is representative of the AL community as a whole. Rather, our sample could be more appropriately characterised as composed of those who were sufficiently interested in OS at the time of the survey (e.g., with a certain level of prior knowledge and interest in OS) to take the time to respond. As will be shown in the following sections, even though our sample was more or less evenly distributed across different career stages, the coverage of research fields and research paradigms was limited, and therefore our findings and conclusions should be interpreted with this limitation in mind. To enhance transparency and reproducibility, the data and $\mathrm{R}$ code for all analyses are available as online supplementary materials for this chapter (also accessible on OSF $^{1}$ and IRIS).

The purpose of the survey was to obtain a preliminary understanding of AL researchers' OS attitudes and practices. Our key questions were:

1. What are applied linguists' attitudes towards open science?

2. To what extent do applied linguistics researchers engage in open practices such as sharing preprints and data?

\footnotetext{
${ }^{1}$ OSF link: https://www.doi.org/10.17605/osf.io/ud3vp
} 
3. To what extent do open science attitudes and practices vary depending on career stage?

4. What are the perceived barriers to open science?

5. To what extent can open science practices be predicted by career stage, attitudes towards open science and perceived barriers?

The structure of the survey is presented in Table 1 below, as an indication of the coverage of OS-related dimensions in this survey.

Table 1 Survey Overview

\begin{tabular}{|c|c|c|c|c|}
\hline \multicolumn{2}{|c|}{ Construct Label } & Item/Question & Format & Role in Analysis \\
\hline \multicolumn{2}{|c|}{$\begin{array}{l}\text { Career Stage } \\
\text { (career_stage) }\end{array}$} & $\begin{array}{l}\text { Year of obtaining } \\
\text { a PhD degree }\end{array}$ & $\begin{array}{l}\text { Continuous/ } \\
\text { Discretised as } 5 \\
\text { categories for } \\
\text { descriptive } \\
\text { analyses }\end{array}$ & $\begin{array}{l}\text { Independent } \\
\text { Variable } \\
\text { (continuous) }\end{array}$ \\
\hline \multicolumn{2}{|c|}{$\begin{array}{l}\text { Research Field } \\
\text { (research_field) }\end{array}$} & $\begin{array}{ll}\text { What } & \text { best } \\
\text { describes } & \text { your } \\
\text { research? } & \end{array}$ & $\begin{array}{l}\text { Nominal + Open- } \\
\text { ended, "Check all } \\
\text { that apply" }\end{array}$ & $\begin{array}{l}\text { Background } \\
\text { Information }\end{array}$ \\
\hline \multicolumn{2}{|c|}{$\begin{array}{l}\text { Research Data Type } \\
\text { (research_data) }\end{array}$} & $\begin{array}{l}\text { What research } \\
\text { data do you (co- } \\
\text { Iproduce? }\end{array}$ & $\begin{array}{l}\text { Nominal + Open- } \\
\text { ended, "Check all } \\
\text { that apply" }\end{array}$ & $\begin{array}{l}\text { Background } \\
\text { Information }\end{array}$ \\
\hline \multirow[t]{5}{*}{$\begin{array}{l}\text { OS } \\
\text { Attitude }\end{array}$} & $\begin{array}{ll}\text { Attitude } & \text { to } \\
\text { Reproducibility } & \\
\text { (att_repro) } & \end{array}$ & $\begin{array}{l}\text { "Research should } \\
\text { be reproducible." }\end{array}$ & $\begin{array}{lr}\text { Ordinal, } & \text { 5-point } \\
\text { Likert } & \text { scale, } \\
\text { Disagree } & \text { - Agree }\end{array}$ & $\begin{array}{l}\text { Independent } \\
\text { Variable }\end{array}$ \\
\hline & $\begin{array}{l}\text { Attitude to Sharing } \\
\text { Data } \\
\text { (att_share_data) }\end{array}$ & $\begin{array}{l}\text { "Data should be } \\
\text { made publicly } \\
\text { available } \\
\text { alongside } \\
\text { publications." }\end{array}$ & $\begin{array}{lr}\text { Ordinal, } & \text { 5-point } \\
\text { Likert } & \text { scale, } \\
\text { Disagree } & \text { Agree }\end{array}$ & $\begin{array}{l}\text { Independent } \\
\text { Variable }\end{array}$ \\
\hline & $\begin{array}{lr}\text { Willingness } & \text { to } \\
\text { Adopt } & \text { Open }\end{array}$ & $\begin{array}{ll}\text { Do you wish (in } \\
\text { principle) }\end{array}$ & $\begin{array}{l}\text { Ordinal, } \\
\text { Likert }\end{array}$ & $\begin{array}{l}\text { Independent } \\
\text { Variable }\end{array}$ \\
\hline & $\begin{array}{l}\text { Practice } \\
\text { (wish_open) }\end{array}$ & $\begin{array}{l}\text { adopt (more) } \\
\text { open science } \\
\text { practices? }\end{array}$ & Disagree - Agree & \\
\hline & $\begin{array}{l}\text { Self-efficacy } \\
\text { Open Practice } \\
\text { (can_open) }\end{array}$ & $\begin{array}{l}\text { Do you believe } \\
\text { you can (or will in } \\
\text { the near future) } \\
\text { adopt (more) } \\
\text { open science } \\
\text { practices? }\end{array}$ & $\begin{array}{lr}\text { Ordinal, } & \text { 5-point } \\
\text { Likert } & \text { scale, } \\
\text { Disagree } & \text { Agree }\end{array}$ & $\begin{array}{l}\text { Independent } \\
\text { Variable }\end{array}$ \\
\hline \multirow[t]{2}{*}{$\begin{array}{l}\text { OS } \\
\text { Practice }\end{array}$} & $\begin{array}{l}\text { Sharing Preprints } \\
\text { (share_preprint) }\end{array}$ & $\begin{array}{l}\text { Do you make } \\
\text { your preprints } \\
\text { publicly } \\
\text { available? }\end{array}$ & Binary & $\begin{array}{l}\text { Recoded } \\
\text { Dependent } \\
\text { Variable }\end{array}$ \\
\hline & Preprint Platforms & $\begin{array}{l}\text { Which } \\
\text { platform(s) do } \\
\text { you use to make } \\
\text { your preprints } \\
\text { available? }\end{array}$ & $\begin{array}{l}\text { Nominal, "Check } \\
\text { all that apply" }\end{array}$ & $\begin{array}{l}\text { Background } \\
\text { Information }\end{array}$ \\
\hline
\end{tabular}




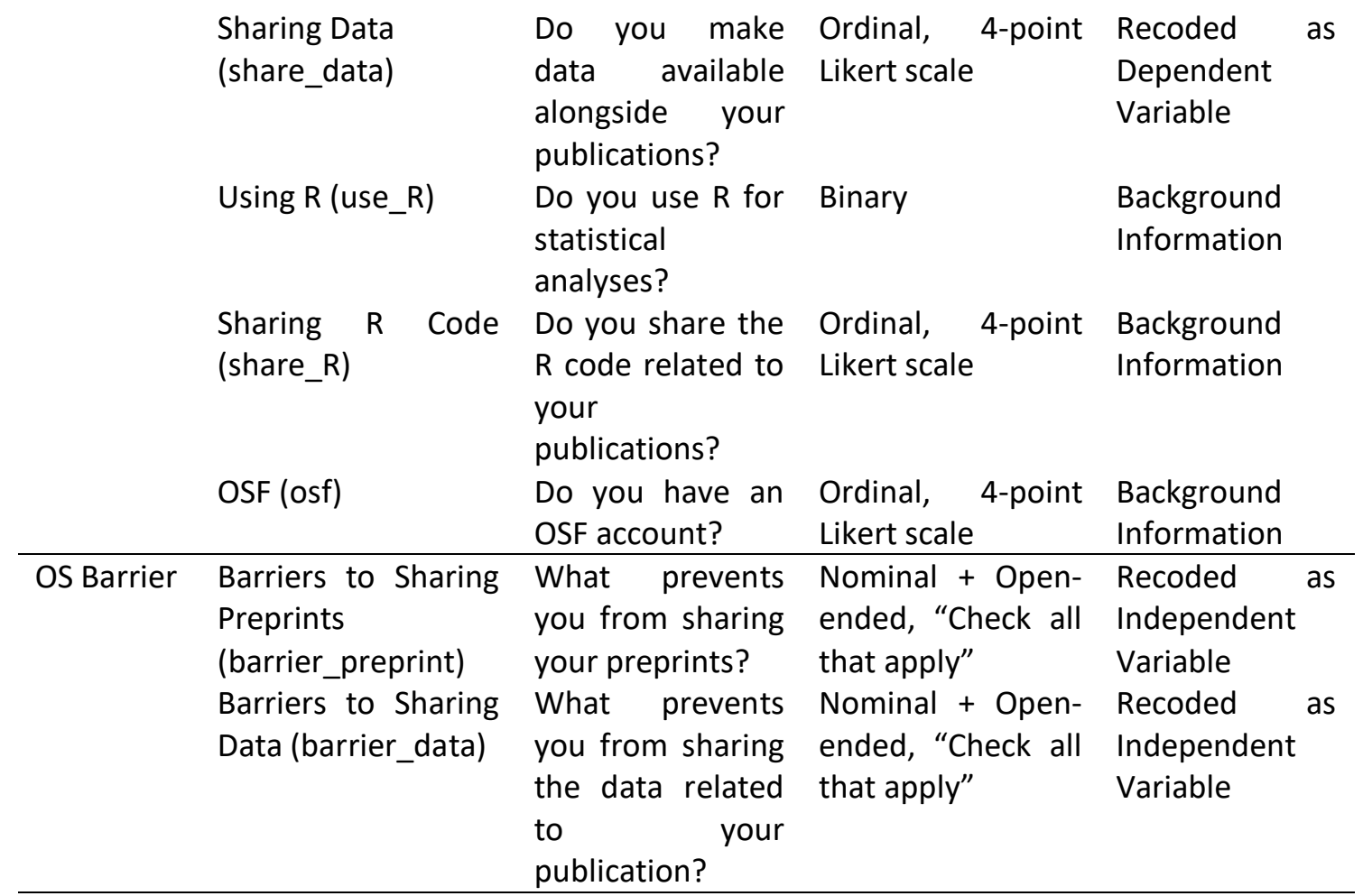

Note. Labels of variables used in the R code are displayed in brackets.

\section{Survey Participants}

\subsection{Career Stage}

A key variable in this study is career stage. Participants were asked to indicate the year of obtaining a PhD degree. To better understand the role of career stage in OS attitudes and practices, we discretised this variable into five categories to facilitate data exploration. We were interested in visually inspecting the patterns of relationships across different career stages and we did not want to assume linear relationships before we examined the data. Therefore, we chose visual exploration over alternatives such as correlation analysis. It should be noted that we only used the discretised version for descriptive analyses. The continuous version of this variable was used for inferential analyses to retain maximum information.

To facilitate visual presentation (i.e., to avoid long headings in the plots), we used short labels in the format of years after PhD to represent the groups: PhD students $(n=23), 0-4$ years $(n=37), 5-10$ years $(n=23), 11-20$ years $(n=40)$ and 20 years above $(n=33)$. It should be noted that the discretisation was conducted before we explored the data and not modified subsequently as the group size was more or less comparable. One participant's response was invalid (and removed from subsequent analyses involving Career Stage) ${ }^{2}$. We created two groups within the first 10 years after PhD completion for two main reasons: First, it is meaningful to have a more refined categorisation within the first decade of career development as this is arguably the most dynamic stage of career development and the one when researchers are mostly vulnerable (e.g., in pursuit of tenure positions), which could influence their OS attitudes and practices. Second, from a practical perspective, it also aligned well with the characteristics of our dataset: Breaking down into two groups resulted

\footnotetext{
2 Additionally, there was a case reported the year as "in the future" and thereby categorised as "PhD student"; There was another case reported the year as "1960", which was most likely a birth year as opposed to year of obtaining PhD and categorised as "20 years above". Because of this inaccuracy, these two cases were only retained in the descriptive analyses stage and excluded from the inferential analyses stage.
} 
in more even group sizes across the stages, an unplanned characteristic that allowed for more meaningful comparisons in descriptive analyses. The cut-off value of four years was chosen according to the definition of Early Career Researchers (ECRs) by the European Research Commission (EURAXESS). We are aware that this cut-off only represents one of the many ways to define ECRs from a temporal perspective. Therefore, we used the exact number of years after PhD as the labels, making it explicit to the reader how we created the groups.

Considering our research interest in career stage as a key factor in OS, visualisation by career stage was our default choice, and in cases when there were no noticeable trends across the career stages, we opted for whole sample plots for parsimony.

\subsection{Research Field}

We surveyed the respondents' research fields, allowing for the option of multiple identifications to reflect the interdisciplinary nature of much AL research. For this reason, we visualised the research fields with two plots: one showing the percentage of responses by selected fields (left panel, Figure 1), the other the number of selected fields by each individual (right panel, Figure 1).

\section{What best describes your research?}

check all that apply; $\mathrm{n}=157$

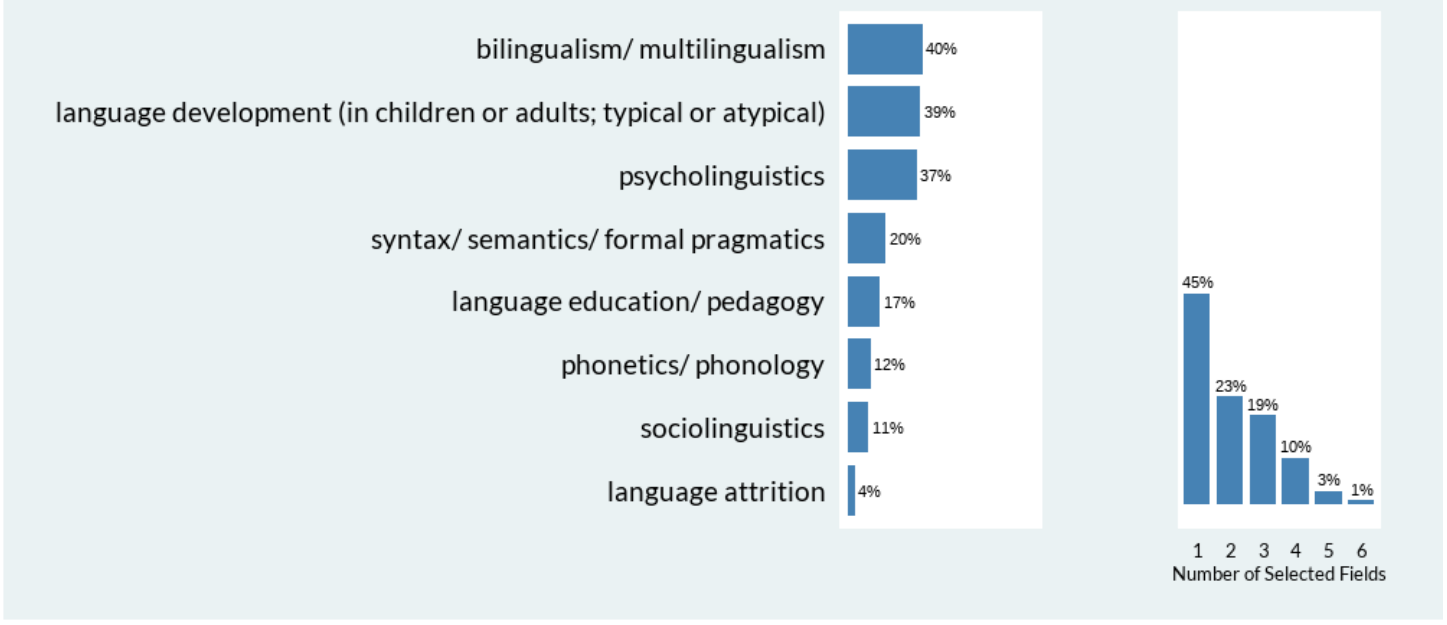

Figure $1^{3}$ Research Field

Note. In the left panel, only fields with percentage higher than $1 \%$ are displayed - see Appendix for the full plot.

As shown in Figure 1, bilingualism and multilingualism, language development and psycholinguistics were the three fields most represented in this sample, with $55 \%$ of researchers identifying with more than one research field. Given the multiplicity of fields most respondents identified with, we did not use Research Field as a predictor in the inferential analyses.

\subsection{Research Data Type}

Participants were asked to indicate what research data they (co-)produce and the responses suggest that our sample was composed essentially of quantitative researchers. No researcher reported only producing qualitative data. Non-quantitative types of data were

\footnotetext{
${ }^{3}$ The total number of valid responses is displayed under the title in all plots.
} 
reported by one individual or none, and therefore not displayed in Figure 2. Most researchers (60\%) produced two or more types of data. Given that overlap, we did not use Research Data Type as a predictor in the inferential analyses.

What research data do you (co-)produce?

check all that apply; $\mathrm{n}=157$

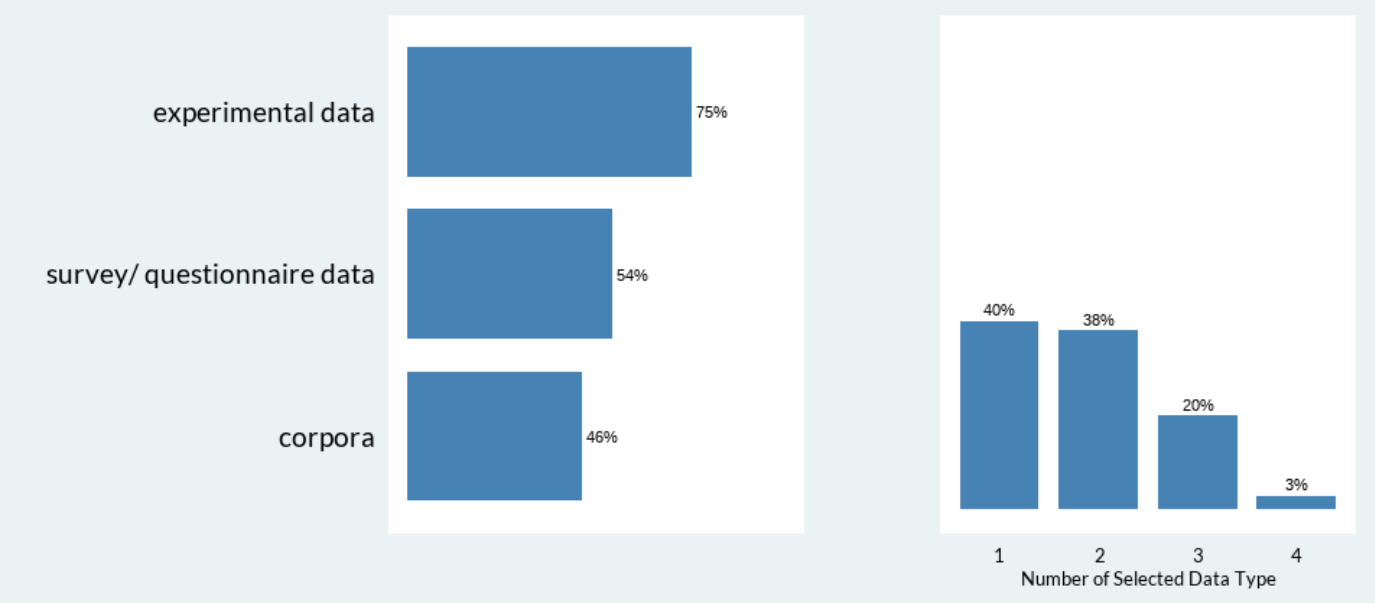

Figure 2 Research Data Type

Note. In the left panel, only fields with percentage higher than $1 \%$ are displayed - see Appendix for the full plot.

\section{Descriptive Analyses: Career Stage and OS}

The descriptive analyses below explore the distribution of OS attitudes and practices across career stages.

4.1 How are OS attitudes distributed across career stages?

As shown in Table 1, we measured OS Attitude in four aspects: Attitude to Reproducibility (Figure 3), Attitude to Sharing data (Figure 4), Willingness to Adopt Open Practice (Figure 5), and Self-efficacy in Open Practice (Figure 6).

\subsubsection{Attitude to Reproducibility}


Research should be reproducible.

$\mathrm{n}=156$

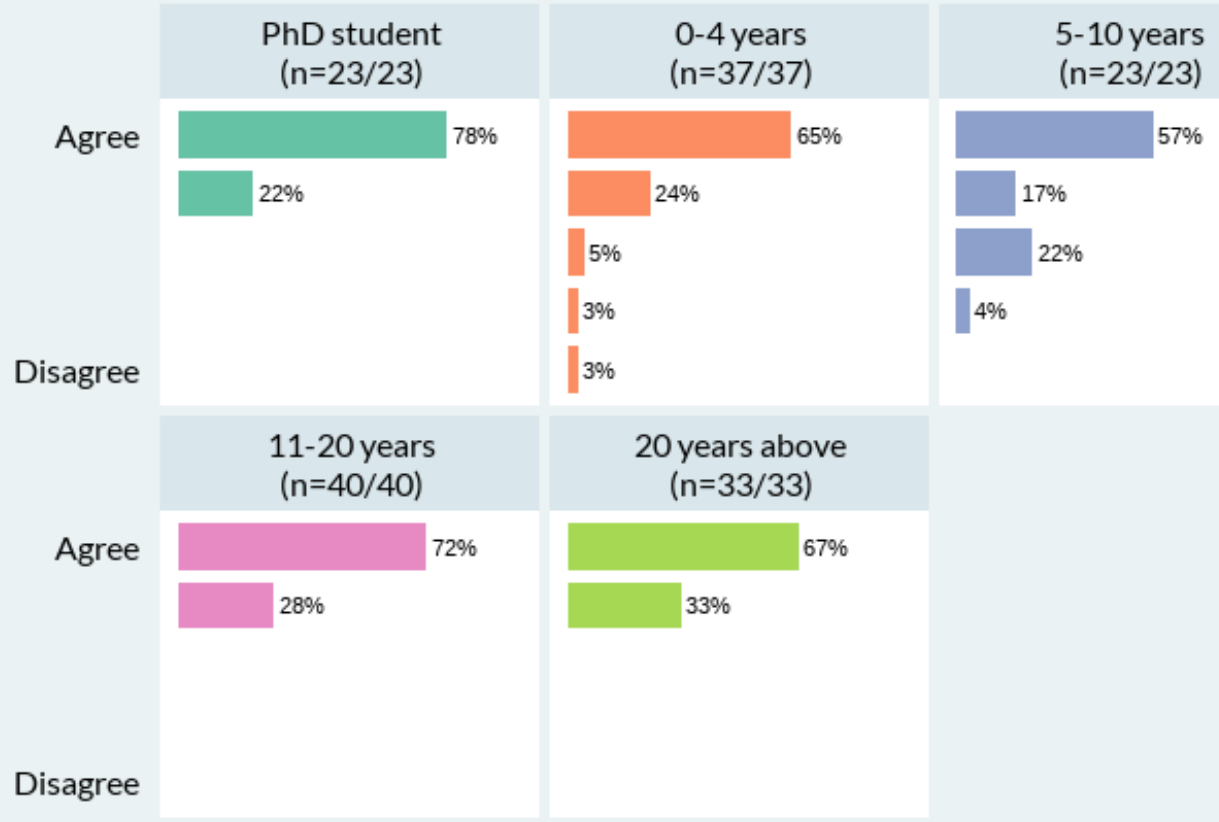

Figure $3^{4}$ Attitude to Reproducibility by Career Stage (Labelled with Years After PhD)

The majority of respondents had positive attitudes towards reproducibility, with PhD students being the most positive and the patterns in two groups slightly deviating from the rest: There was a small number of researchers in 0-4 years and 5-10 years who reported neutral or slightly negative attitudes.

\subsubsection{Attitude to Sharing Data}

${ }^{4}$ The panel for each career stage is labelled in the following format: Career Stage ( $n=$ number of valid responses / group size). All "by Career Stage" plots follow the same format. 
Data should be made publicly available alongside publications. $\mathrm{n}=156$

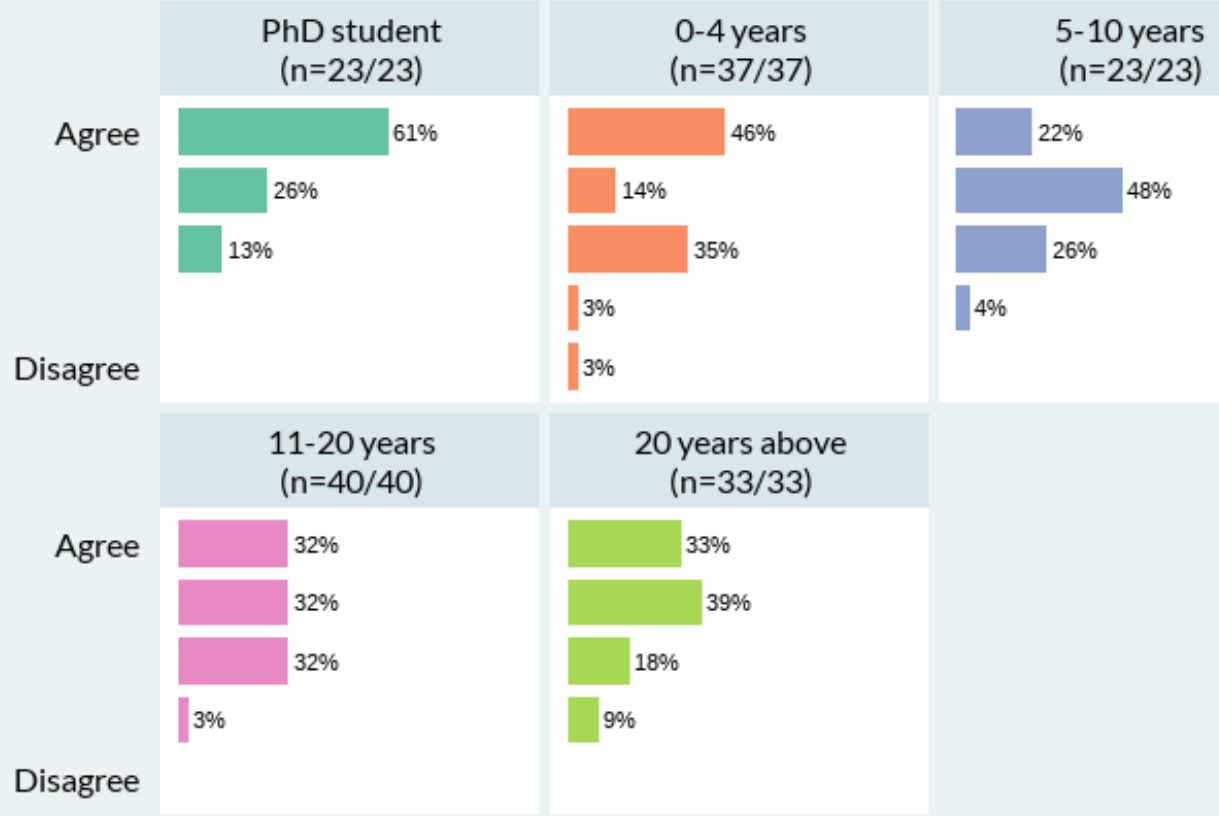

Figure 4 Attitude to Sharing Data by Career Stage (Labelled with Years After PhD)

Regarding attitudes to data sharing, over half of the participants scored in the top two categories, suggesting an overall positive attitude especially for PhD students. Nevertheless, a significant portion of the participants selected the middle option, indicating either neutral or mixed attitudes towards data sharing. In contrast to attitudes to reproducibility, there were visibly more participants who reported negative attitudes in all groups except PhD students. This means that data sharing was perceived as more complicated by researchers in this sample.

\subsubsection{Willingness to Adopt Open Practice}


Do you wish (in principle) to adopt (more) open science practices? $n=156$

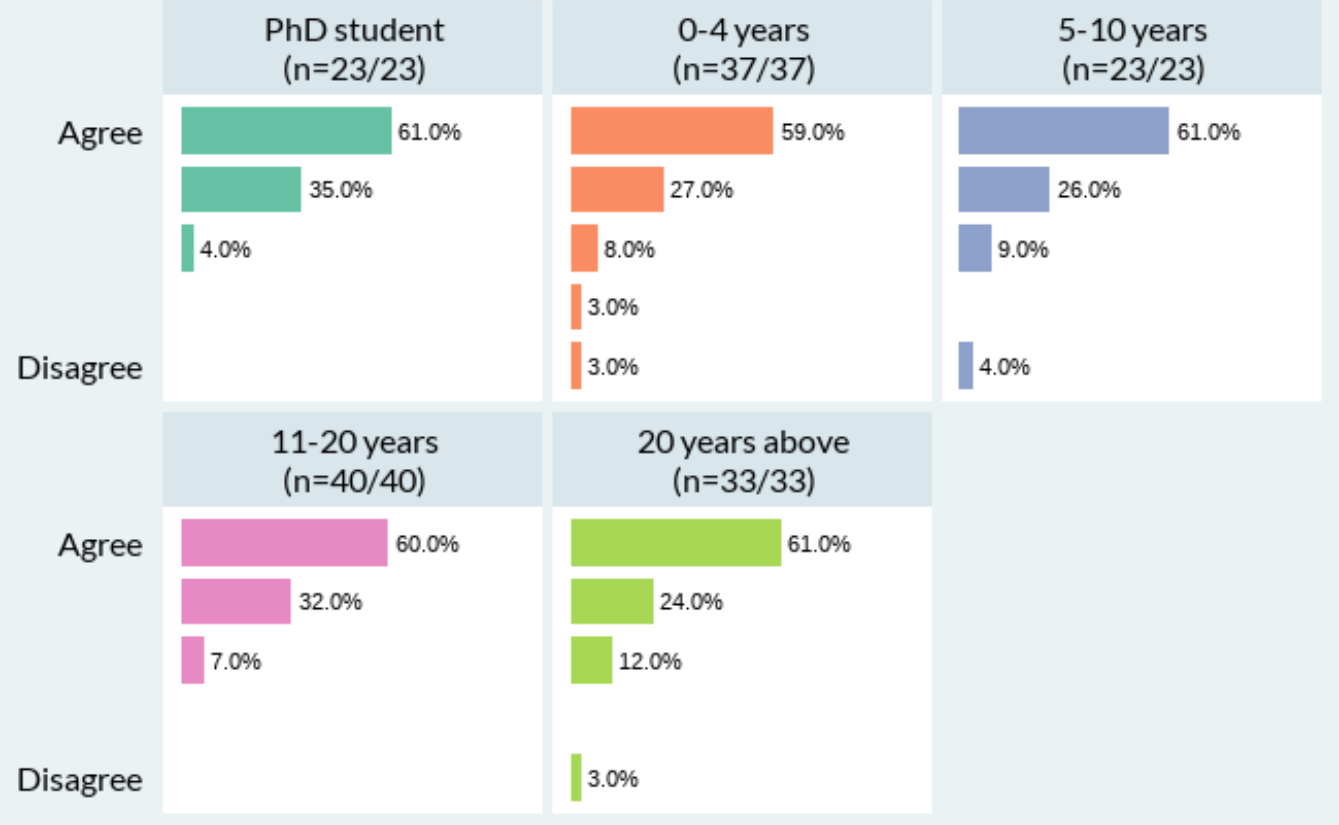

Figure 5 Willingness to Adopt Open Practice by Career Stage (Labelled with Years After PhD)

All groups reported a similar pattern of high levels of willingness to adopt more open practices. Similar to the patterns regarding reproducibility, the 0-4 years and 5-10 years groups featured a small minority with more negative attitudes.

\subsubsection{Self-efficacy in Open Practice}


Do you believe you can (or will in the near future) adopt (more) open science practices?

$\mathrm{n}=156$

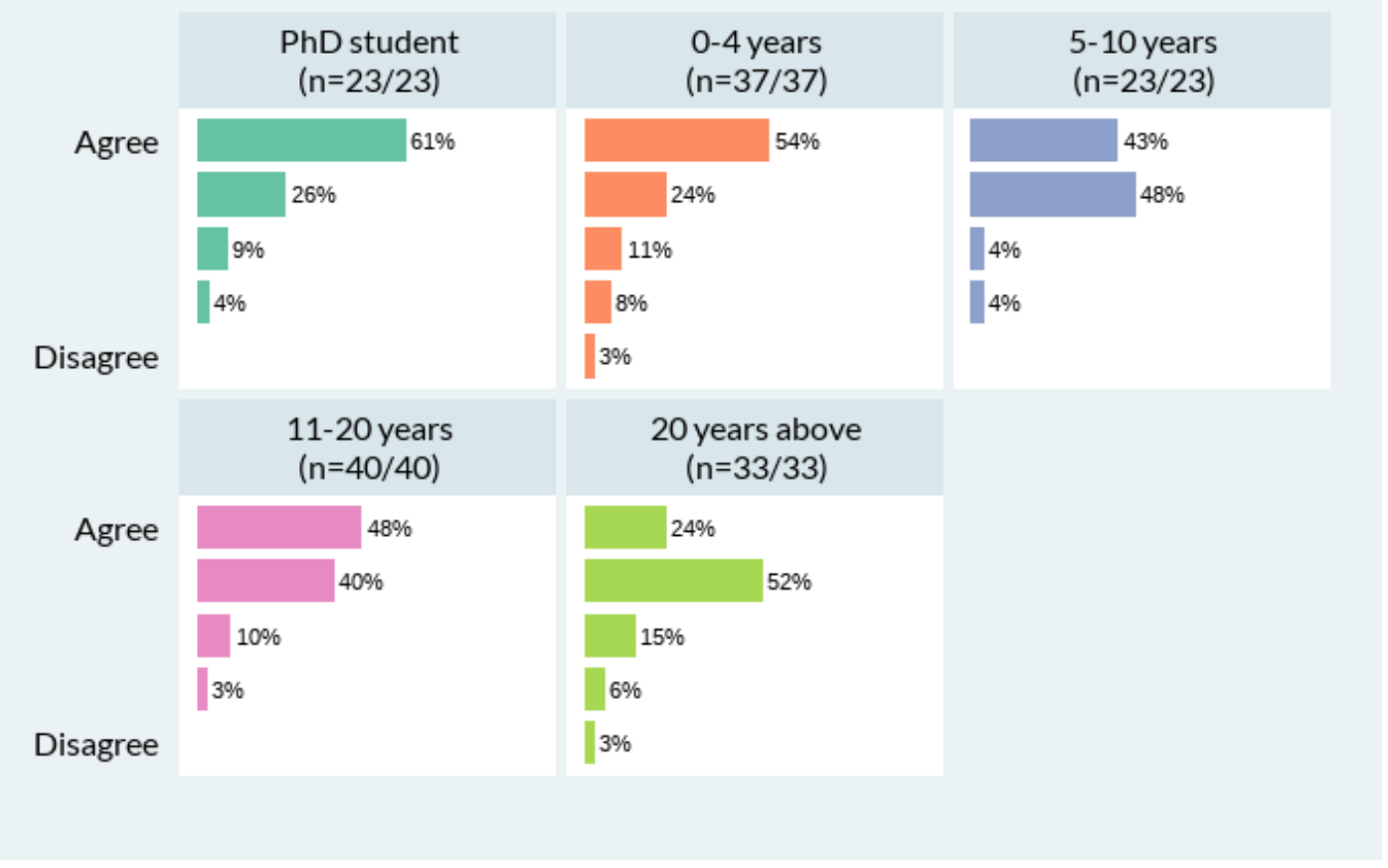

Figure 6 Self-efficacy in Open Practice by Career Stage (Labelled with Years After PhD)

Regarding self-efficacy in open practices, PhD students had the highest self-efficacy whereas the more senior groups had comparatively lower self-efficacy.

To better understand the deviations in $0-4$ years and 5-10 years observed in most OS attitudes, a post hoc follow-up analysis was conducted to see whether it was the same individuals who were less positive across these questions (see Appendix for details). There were six individuals who scored less than the mid-point (i.e., 3) in either three or all four of the OS attitudes questions, indicating a moderate level of overlap (with the total number of people with below mid-point scores in each question ranging from 8 to 22). This indicates that there was some heterogeneity when it comes to OS attitudes, where early to midcareer researchers had slightly less positive attitudes. A potential reason could be the instability and vulnerability associated with the early stage in the career trajectory. It is understandable if a researcher is under pressure to secure a tenure position, the willingness to share data may be lower due to fear of judgement or being scooped. Another potential contributing and confounding factor would be the insufficient coverage of qualitative researchers in the sample. It appears that the few researchers who were involved in qualitative research happened to be in the early to mid-career range. We would hypothesise that researchers subscribing to qualitative research paradigms would have less positive OS attitudes than those subscribing to quantitative research paradigms, regardless of career stages.

4.2 How are OS practices distributed across career stages?

As shown in Table 1, we measured OS Practice with six questions: Sharing Preprints (Figure 7), Preprint Platforms (Figure 8), Sharing Data (Figure 9), Using R (Figure 10), Sharing R Code (Figure 11), and having an OSF account (Figure 12).

\subsubsection{Sharing Preprints}




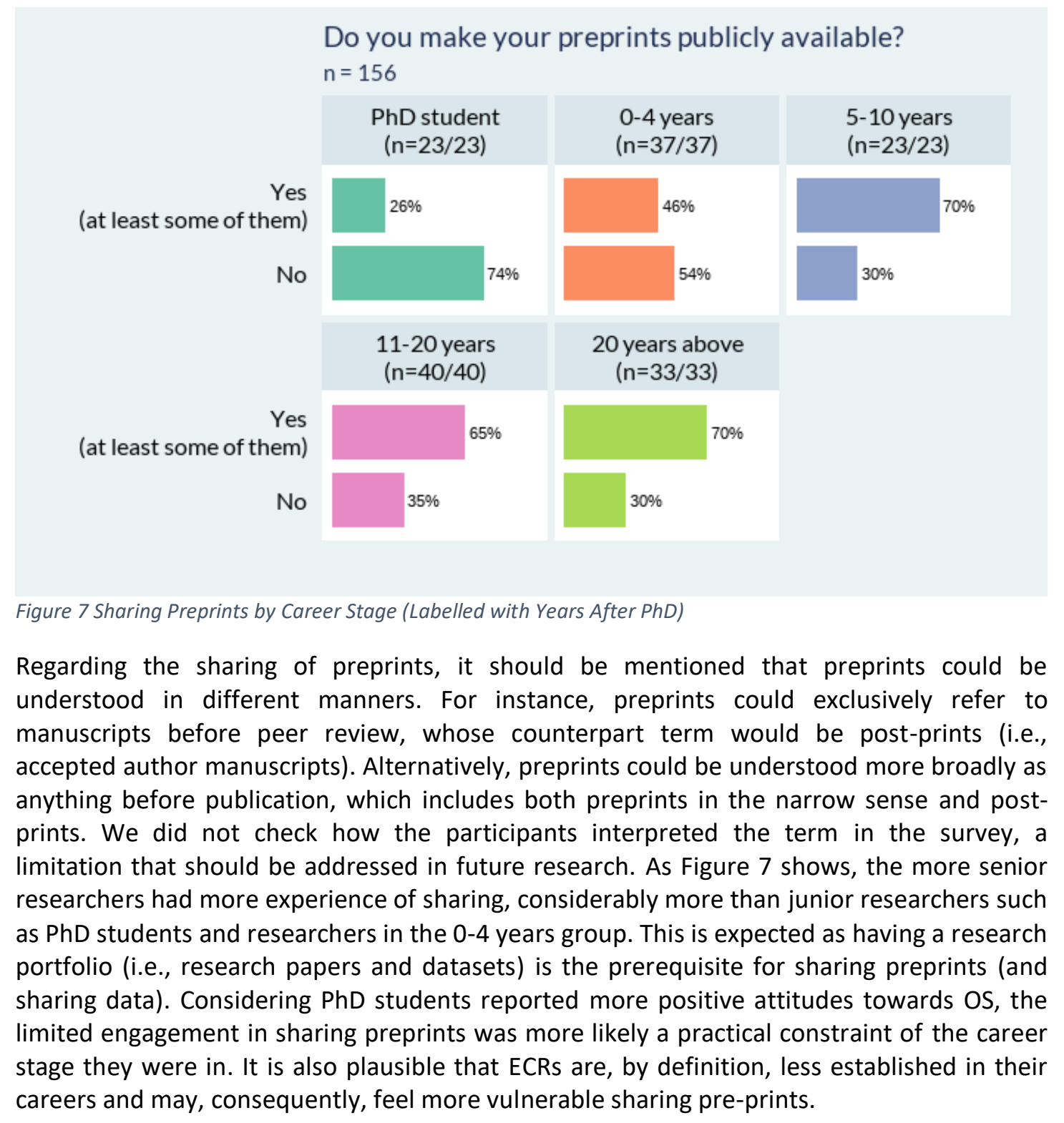

\subsubsection{Preprint Platforms}


Which platform(s) do you use to make your preprints available?

Check all that apply; $\mathrm{n}=89$

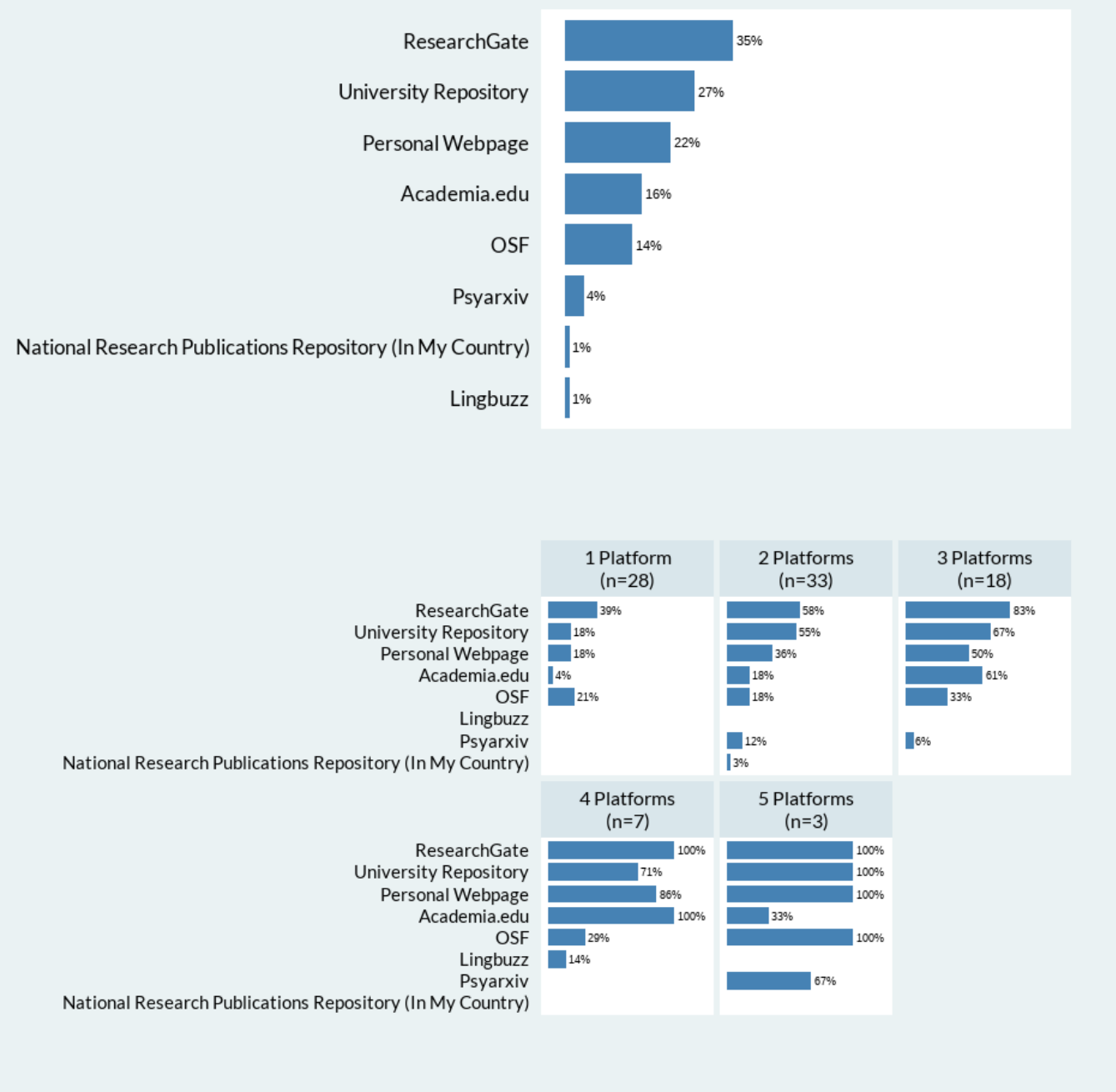

\section{Figure 8 Preprint Platforms}

To better understand the practices of sharing preprints, participants were also asked to indicate what platform(s) they used. No noticeable between-group trends were observed, and we therefore presented the responses by the sample as a whole for parsimony.

Most researchers who used preprint platforms selected two platforms while the most popular platforms were ResearchGate, University Repository and Personal Webpage, regardless of how many platforms people used. We need to highlight that this is not an exhaustive list of preprint platforms. Future research should consider other platforms to examine whether differences in preferences for particular platforms exist across career stages.

\subsubsection{Sharing Data}




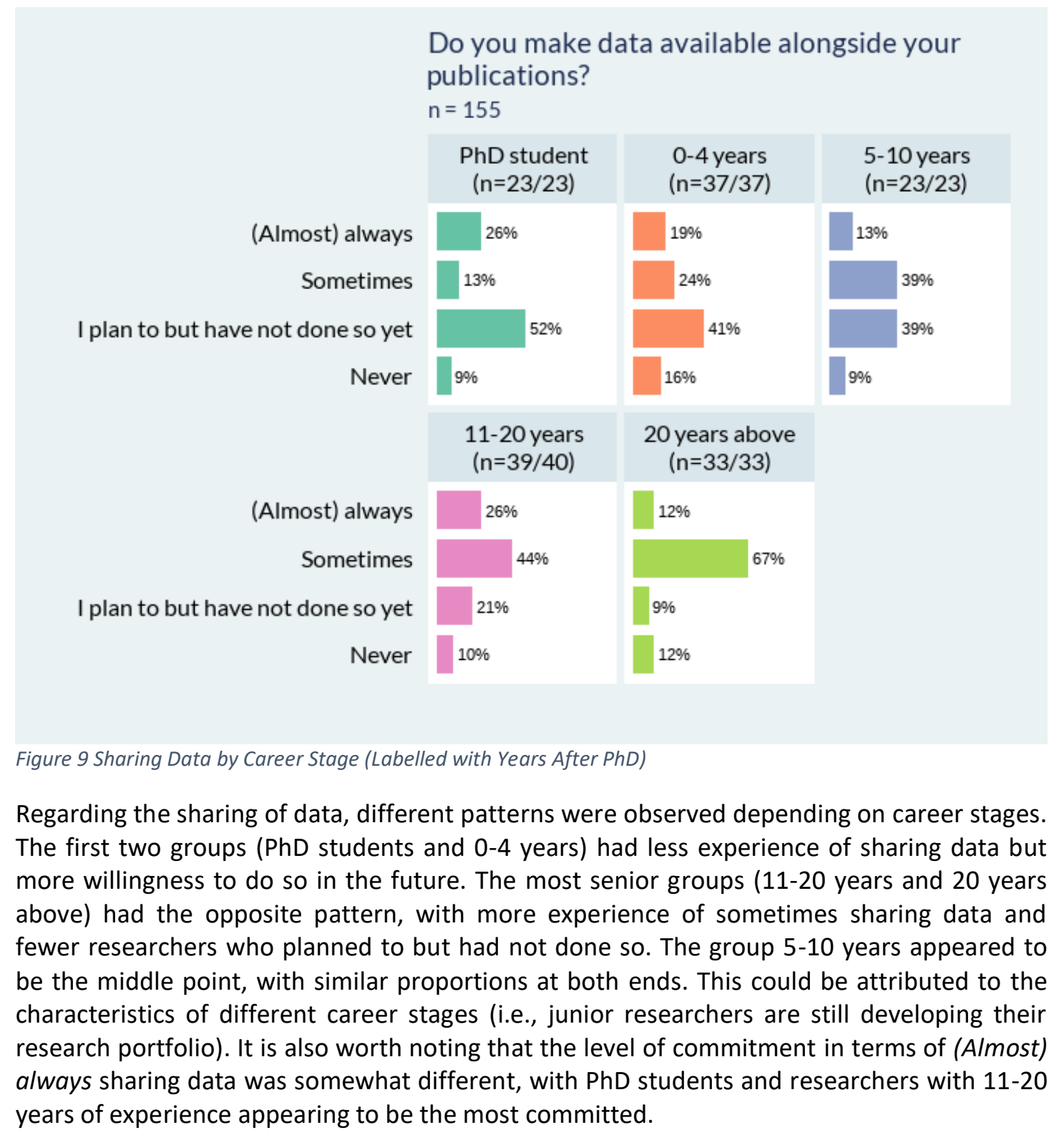

\subsubsection{Using $R$}




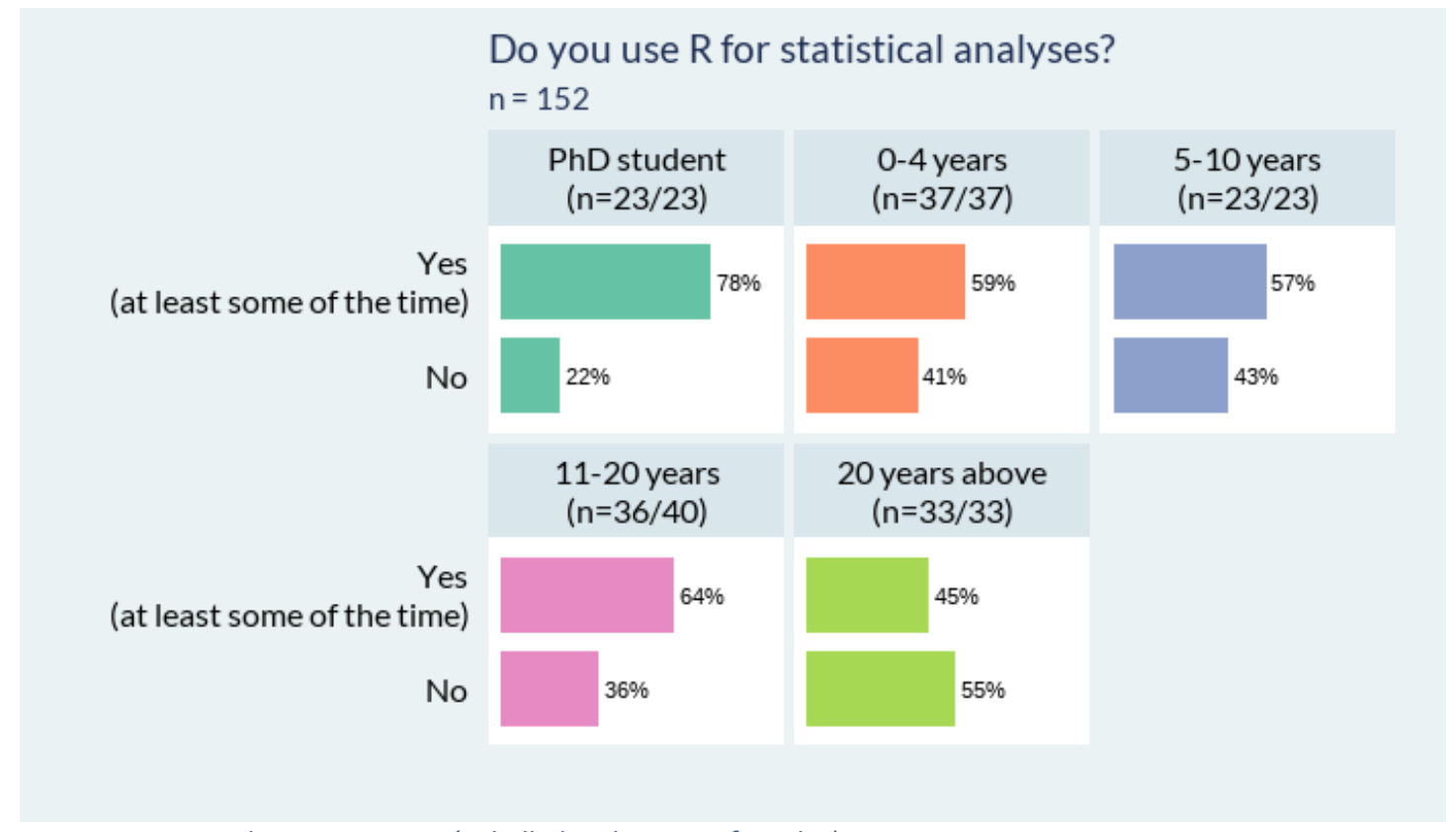

Figure 10 Using R by Career Stage (Labelled with Years After PhD)

Regarding the use of $\mathrm{R}, \mathrm{PhD}$ students had the highest rate of $\mathrm{R}$ use, while the most senior group (i.e., 20 years above) had the lowest rate. Future research should include other OS compatible software packages or programming languages (e.g., Stata, Mplus, Python) to fully capture the use of analysis scripts across career stages.

\subsubsection{Sharing $R$ Code}

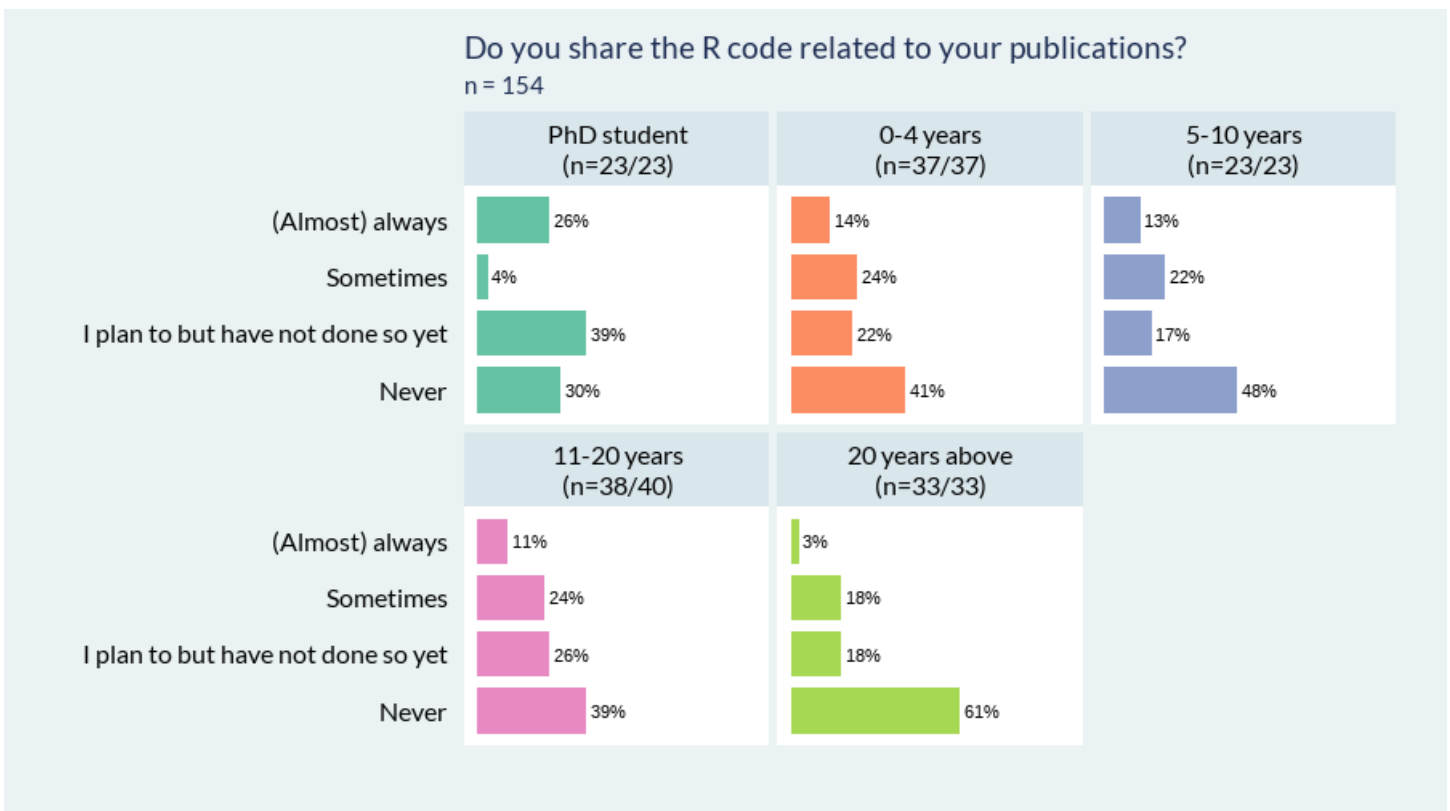

Figure 11 Sharing $R$ Code by Career Stage (Labelled with Years After PhD)

Regarding the sharing of $R$ code, several patterns can be observed. First, compared with the prevalence of $\mathrm{R}$ use, the prevalence of (almost) always sharing was much lower, indicating the presence of certain barriers to code sharing. Still, the biggest gap existed between PhD student and 20 years above, with latter having extremely low rate of always sharing R code and the highest rate of never sharing $\mathrm{R}$ code. In terms of willingness to share in the future, 
PhD students had the highest proportion, indicating the most positive attitudes towards adopting this practice in the future, a pattern similar to that of sharing data.

\subsubsection{OSF}

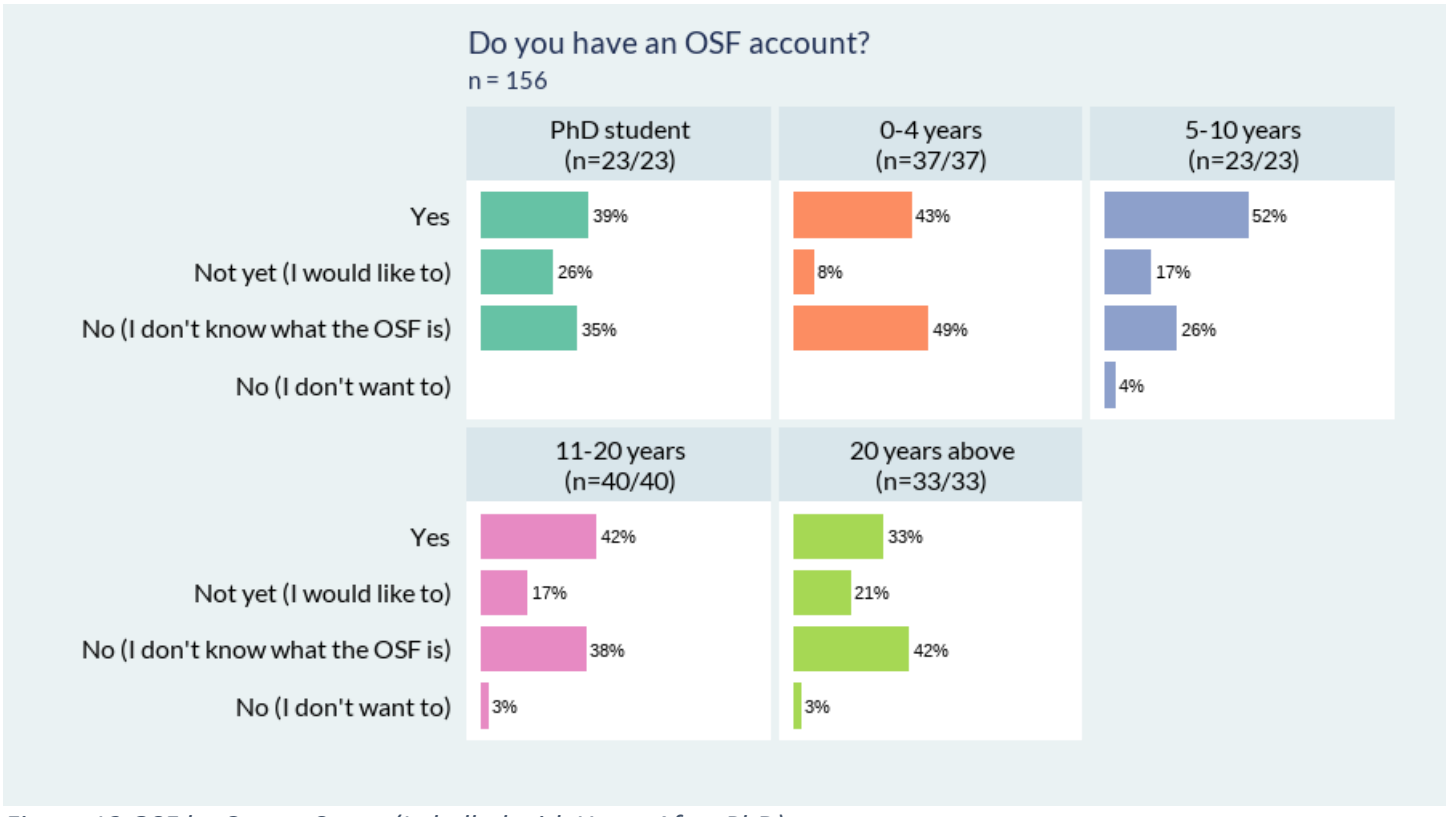

Figure 12 OSF by Career Stage (Labelled with Years After PhD)

Overall, less than half of the participants had an OSF account and there was a significant portion of researchers in all groups that did not know what OSF was, which could indicate a lack of awareness of the existing infrastructures for open practices. It should be mentioned that OSF is only one of the many other open repositories, such as IRIS, TROLLing and GitHub.

Even though data on Using R, Sharing R Code and OSF were informative in the descriptive analyses stage, they were limited and potentially biased representations of open practices, and therefore were excluded from the inferential analyses.

Taken together, what we see is an overall positive attitude towards OS, though with some nuances across career stages. PhD students had the most positive attitudes but least experience in OS practice. More senior researchers engaged more in OS practice in general, and had slightly less positive attitudes, though there were some deviations in terms of attitudes in the early to mid-career groups (0-10 years).

\subsection{What are the perceived barriers to OS practices across career stages?}

To better understand challenges in adopting OS practices, participants were asked to indicate what prevented them from sharing preprints and data, with the option of providing open-ended answers. For each OS practice, data are presented in three parts: The first part is a visualisation of pre-specified response options to show the distribution of responses across career stages (Figure 13, Figure 15). The second part is a visualisation of how many options were selected by respondents in each group (Figure 14, Figure 16). The third part is a table with the open-ended responses supplied by the participants (Table 2, Table 3 ).

\subsubsection{Barriers to Sharing Preprints}




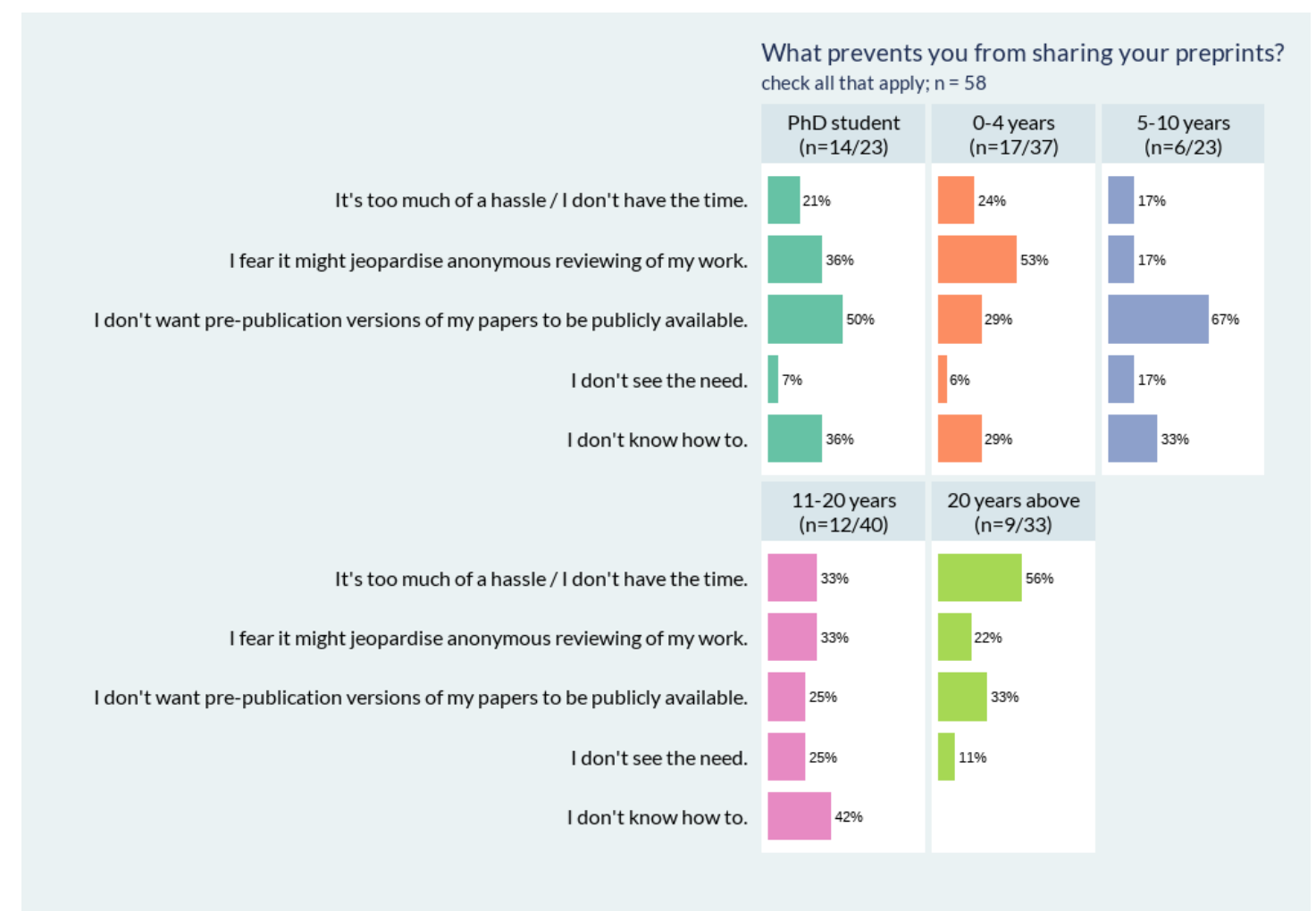

Figure 13 Barriers to Sharing Preprints by Career Stage (Labelled with Years After PhD) - Pre-specified Responses

It should be noted that only a small portion of participants used the pre-specified options ( $\mathrm{n}$ $=58$ ). Among these participants, all the pre-specified reasons were confirmed as actual barriers at (almost) all career stages, while the pattern in each career stage was somewhat different. As will be shown in following plot (Figure 14), most respondents selected just one reason. Taken together, this suggests that there was no single main barrier to the sharing of preprints across the groups. 


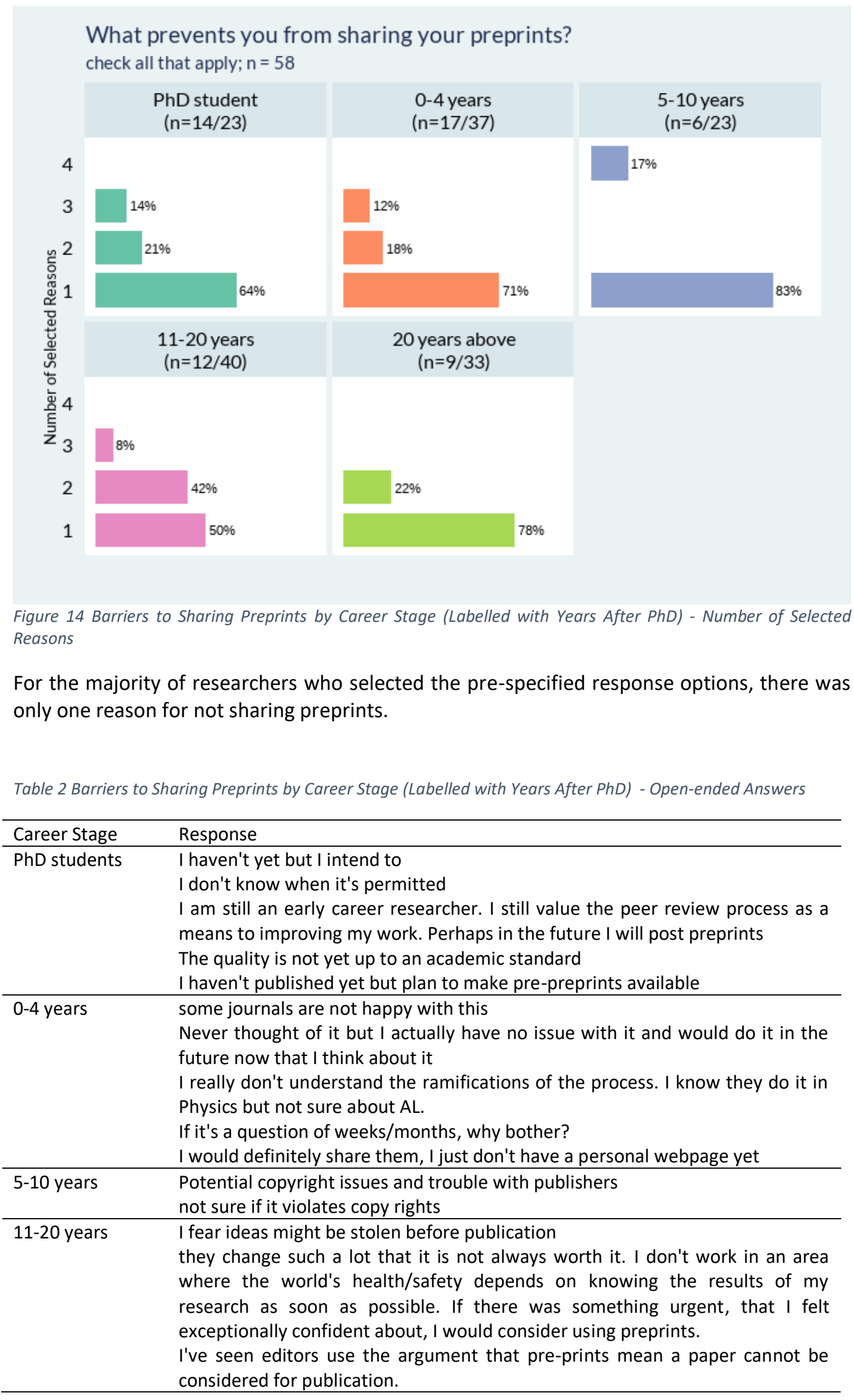


I feel it sometimes confuses the academic process: I often have multiple versions, forgot which version I extracted my knowledge from and it takes too much time sorting out my library and keeping up to date with all the revisions. I'm not in research anymore

20 years above I just had no time to consider it in detail so far but I would be definitely willing to make it in the future.

Note. Career Stage was operationalised as years after PhD. During data wrangling, user supplied opened-ended answers were manually cleaned (see Appendix for details). Typos were corrected.

The open-ended answers revealed many other barriers to sharing preprints. Peer review, journal policy, lack of knowledge of the process, copyright issues, utility of sharing preprints, time constraints and issues in managing preprints were raised as additional barriers. This reflects the need for greater discussion on OS related issues, as some of the barriers could be more easily resolved (e.g., managing preprints, knowledge of the process) while others may require more deliberation and field-wide effort to resolve (e.g., journal policy).

\subsubsection{Barriers to Sharing Data}

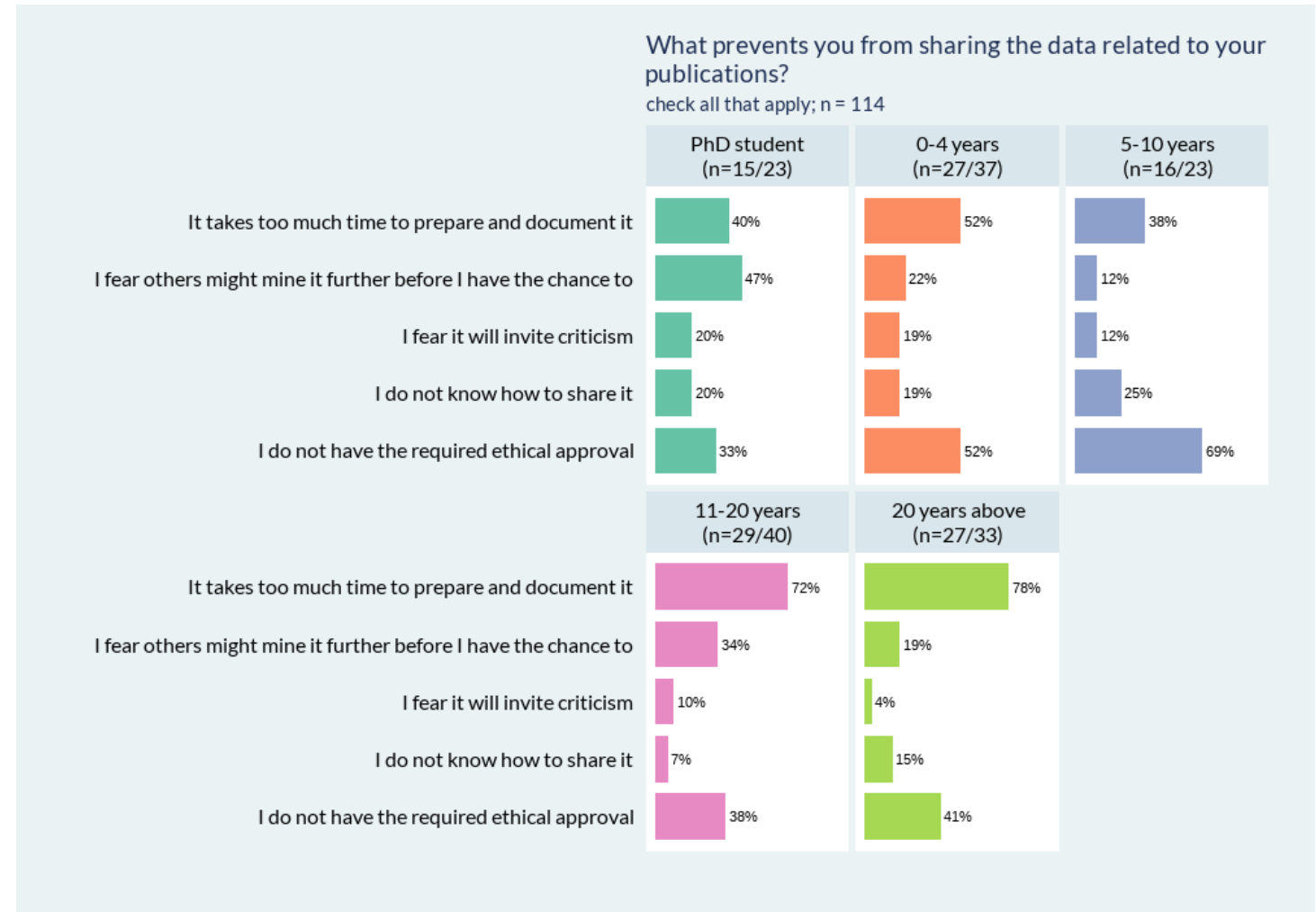

Figure 15 Barriers to Sharing Data by Career Stage (Labelled with Years After PhD) - Pre-specified Responses

Among all the pre-specified barriers, time and ethics appeared to be the two main reasons across most of the groups, with the exception of the PhD students who seemed most affected by the fear of being scooped. This, again, reflects the different characteristics associated with different career stages and thereby different priorities and perceived barriers to open practices. 


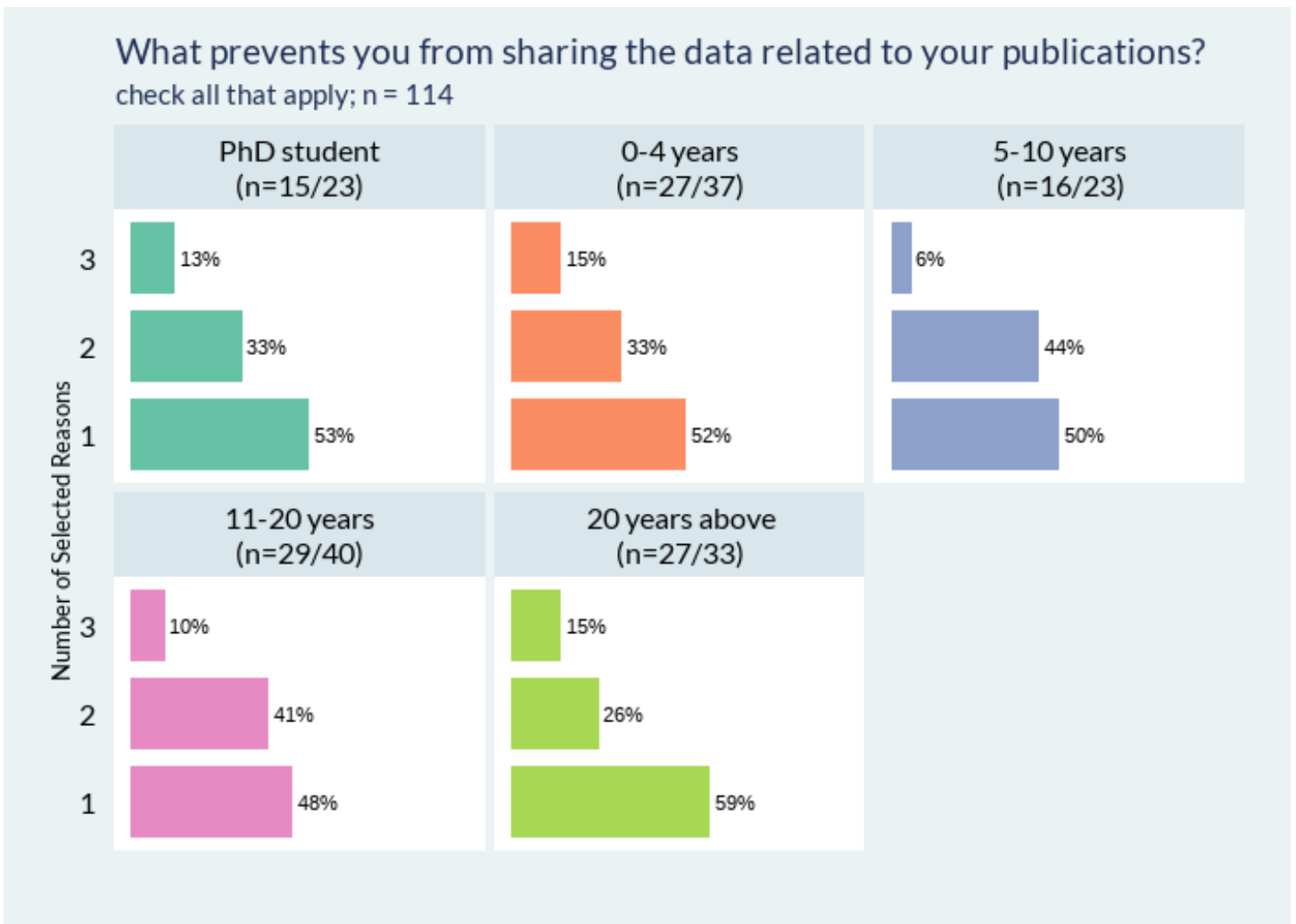

Figure 16 Barriers to Sharing Data by Career Stage (Labelled with Years After PhD) - Number of Selected Reasons

Compared with sharing preprints, we see more people selecting more than one reason, suggesting that the sharing of data is perceived as more complicated than the sharing of preprints.

Table 3 Barriers to Sharing Data by Career Stage (Labelled with Years After PhD) - Open-ended Answers

\begin{tabular}{|c|c|}
\hline Career Stage & Response \\
\hline PhD students & $\begin{array}{l}\text { I will share my data once I have finished my project so that a complete dataset } \\
\text { can be made available (longitudinal data) } \\
\text { it is not allowed according to the ethical committee } \\
\text { I haven't published yet but I plan to share my data }\end{array}$ \\
\hline $0-4$ years & $\begin{array}{l}\text { The data is easy to reproduce. } \\
\text { some data I use is not 'mine' to share (e.g., from operational language tests) } \\
\text { I have to ask all my collaborators } \\
\text { I want to share my data } \\
\text { I said so :) I am worried that someone will spot a mistake or criticize but I can } \\
\text { sacrifice anxiety for sake of quality and scientific process. } \\
\text { Ethnographic data is very sensitive and personal and safeguarding participants' } \\
\text { anonymity is common practices. } \\
\text { I don't know if it's absolutely ok to do it }\end{array}$ \\
\hline $5-10$ years & $\begin{array}{l}\text { I still want to use the database for other analyses and therefore only make it } \\
\text { available upon request } \\
\text { often no place available (in paper publications) } \\
\text { I haven't for previous publications as I hadn't stored it with open access in } \\
\text { mind } \\
\text { Copyright issues (I cannot publish corpora that were compiled by others) } \\
\text { I only do it when requested } \\
\text { I am unsure about the ethical approval and there is too little time to sort this } \\
\text { out. }\end{array}$ \\
\hline
\end{tabular}




\begin{tabular}{l}
\hline I collect qualitative data - even though many IRB ${ }^{5}$ offices don't even consider it \\
data because of the quantitative bias in research (also found in your options \\
throughout by the way ;-) ) it's data that is very personal even if de-identified \\
I am not sure it would be useful to others - it is too specific. I am also worried \\
about it being misused and feel uncomfortable with sharing data collected \\
from kids even though it is anonymised. \\
Many longstanding projects were not designed with data release in mind. \\
PhD candidates are still working on parts of the data \\
I do not know where to save/keep it \\
since I never know/knew how long I will be at one and the same university. \\
I am intimidated by the super-R-users who share shiny markdown scripts and \\
will laugh at my clunky R scripts \\
See above \\
It really depends on the type of data: corpora - yes, other material - yes, \\
sometimes, depending on publication venue and data. \\
All my primary data is already archived in language archives \\
It can be accessed under licence
\end{tabular}

Note. During data wrangling, user supplied opened-ended answers were manually cleaned (see Appendix for details). Typos were corrected.

The complexity involved with sharing data was visible from the open-ended responses. Sensitive data, confidentiality issues, data types, fear of judgement, lack of knowledge, policies and regulations were some additional barriers. It is particularly noticeable that more negative emotions were expressed in these response, concerning the fear of being criticised or "laughed at" (11-20 years, Table 3). The vulnerability inherent in the open practices is worth discussing, as a number of factors could have contributed. For instance, the current level of open practices in AL could be considered as low, making those who adopt open practices necessarily the minority. As a result, the risk inherent in adopting open practices is particularly high, when only the open researchers are subject to public scrutiny. Another interesting theme emergent from these answers was the issue of paradigm differences. The sharing of qualitative data is still an unresolved issue (e.g., the "quantitative bias" mentioned by a participant in the 5-10 years group, Table 3), with concerns regarding confidentiality and utility of open qualitative data.

\section{Inferential Analyses: Predicting OS}

Our inferential analyses were based on one central question: What predicts OS practices? To allow for additional insights beyond what was revealed in the previous section, a number of transformations were performed. To capture OS practices, we used the data on Sharing Preprints and Sharing Data to create a composite ordinal variable to capture OS practices, with three ordered levels ("Sharing Neither", "Sharing Preprints or Data", "Sharing Both"). Year of obtaining a PhD was transformed into the continuous measure of Career Stage, where the year of obtaining a PhD degree was subtracted from 2021, with values ranging from -4 to 42 . The decision to use this continuous measure, as opposed to the categorial version used in the descriptive analyses, was to retain maximum information and thereby facilitate model estimation. We also combined Barriers to Sharing Preprint and Barriers to Sharing Data into five binary variables, each capturing a type of barrier to OS, as reported in Table 4.

\footnotetext{
${ }^{5}$ IRB: Institutional Review Board, a type of committee that reviews research proposals to ensure that the researchers are adhering to certain ethical standards.
} 


\begin{tabular}{|c|c|}
\hline $\begin{array}{l}\text { New Composite Measures } \\
\text { of OS Barrier }\end{array}$ & Original Response Options \\
\hline \multirow[t]{2}{*}{ Insecurity } & $\begin{array}{l}\text { Barriers to Sharing Preprint: } \\
\text { "I fear it might jeopardise anonymous reviewing of my work.", } \\
\text { "I don't want pre-publication versions of my papers to be } \\
\text { publicly available." }\end{array}$ \\
\hline & $\begin{array}{l}\text { Barriers to Sharing Data: } \\
\text { "I fear it will invite criticism.", } \\
\text { "I fear others might mine it further before I have the chance } \\
\text { to." }\end{array}$ \\
\hline \multirow[t]{2}{*}{ Practicality } & $\begin{array}{l}\text { Barriers to Sharing Preprint: } \\
\text { "It's too much of a hassle / I don't have the time.", } \\
\text { "I don't know how to." }\end{array}$ \\
\hline & $\begin{array}{l}\text { Barriers to Sharing Data: } \\
\text { "I do not know how to share it.", } \\
\text { "It takes too much time to prepare and document it." }\end{array}$ \\
\hline Necessity & $\begin{array}{l}\text { Barriers to Sharing Preprint: } \\
\text { "I don't see the need." }\end{array}$ \\
\hline Ethics & $\begin{array}{l}\text { Barriers to Sharing Data: } \\
\text { "I do not have the required ethical approval." }\end{array}$ \\
\hline Other & $\begin{array}{l}\text { User-supplied open-ended answers from Barriers to Sharing } \\
\text { Preprint and Barriers to Sharing Data (Table 2, Table 3) }\end{array}$ \\
\hline
\end{tabular}

Note. The composite measures were binary (with values 0 and 1 ). The values of 1 indicates the presence of at least one of the items listed for the multi-item scales.

Ordinal logistic regression was performed using the MASS package in R version 4.0.3 with the composite measure of OS Practice as the dependent variable, and key variables of interest, namely Career Stage, OS Attitude and OS Barrier as predictors (Table 5, Figure 17). Model parameter estimates were transformed to odds ratio (OR), an effect size measure, to facilitate interpretation.

Table 5 Ordinal Logistic Regression Results

\begin{tabular}{|c|c|c|c|c|c|c|}
\hline Construct & Variable & OR & SE & $\mathrm{t}$ & $p$ & $95 \% \mathrm{Cl}$ \\
\hline Career Stage & Years After PhD & 1.08 & 0.02 & 3.94 & $<.001$ & {$[1.04,1.12]$} \\
\hline \multirow{4}{*}{ OS Attitude } & Attitude to Reproducibility & 0.71 & 0.27 & -1.25 & .211 & {$[0.41,1.22]$} \\
\hline & Attitude to Sharing Data & 1.72 & 0.26 & 2.08 & .037 & {$[1.04,2.89]$} \\
\hline & Willingness to Adopt Open Practice & 0.66 & 0.35 & -1.2 & .231 & {$[0.32,1.3]$} \\
\hline & Self-efficacy in Open Practice & 1.19 & 0.27 & 0.63 & .53 & {$[0.69,2.04]$} \\
\hline \multirow{3}{*}{ OS Barrier } & Insecurity: Yes & 0.14 & 0.39 & -5.07 & $<.001$ & {$[0.06,0.29]$} \\
\hline & Practicality: Yes & 0.25 & 0.39 & -3.5 & $<.001$ & {$[0.12,0.54]$} \\
\hline & Necessity: Yes & 0.25 & 0.84 & -1.65 & .098 & {$[0.05,1.24]$} \\
\hline
\end{tabular}




\begin{tabular}{llllll} 
Ethics: Yes & 0.91 & 0.39 & -0.25 & .804 & {$[0.42,1.96]$} \\
Other: Yes & $\mathbf{0 . 2 2}$ & $\mathbf{0 . 4 3}$ & $\mathbf{- 3 . 5 4}$ & $<.001$ & {$[\mathbf{0 . 0 9 , 0 . 5 ]}$} \\
\hline Sharing Neither | Share Preprint or Data & 0.03 & 1.46 & -2.53 & .012 & \\
Share Preprint or Data| Share Both & 0.35 & 1.43 & -0.73 & .463 & \\
\hline
\end{tabular}

Note. $n=154$. Significant predictors are displayed in bold.

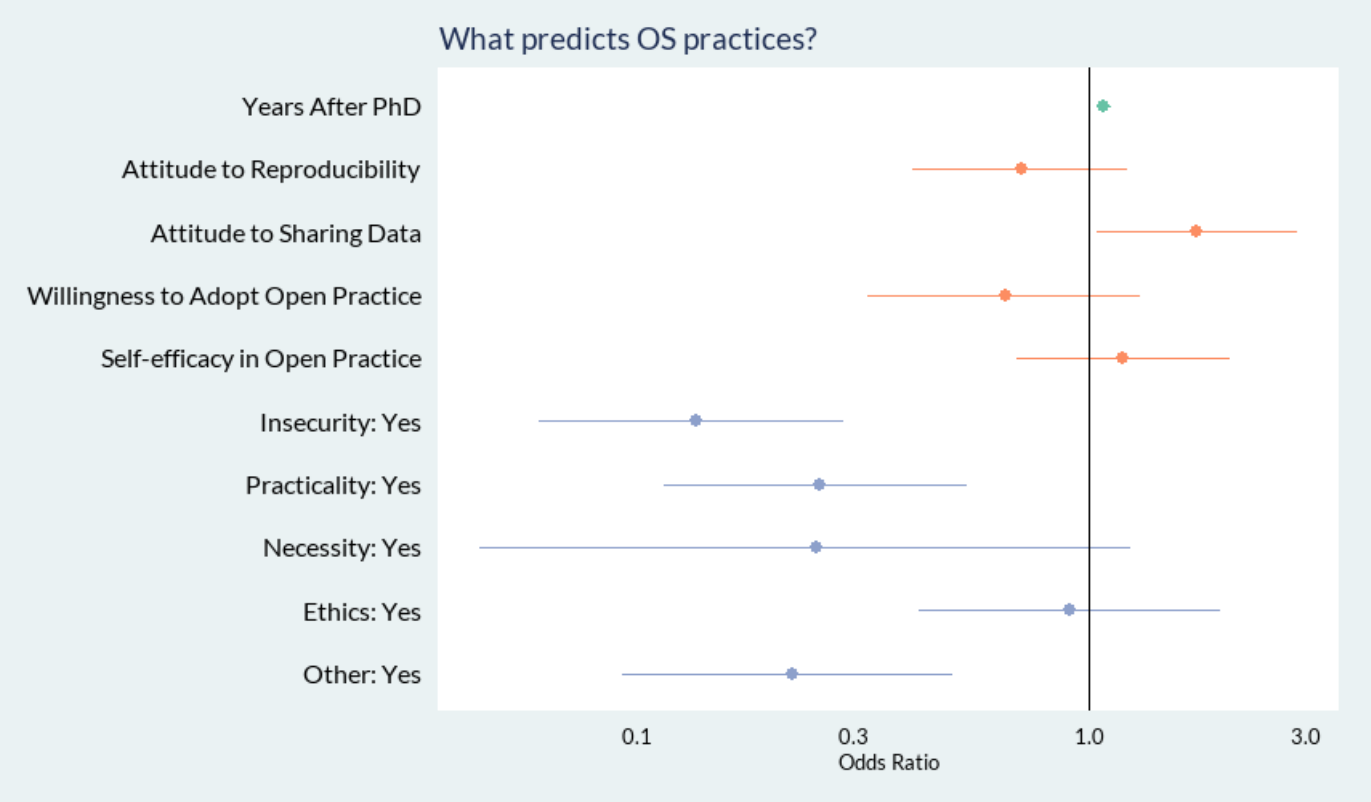

Figure 17 Odds Ratio Plot

Note. Line segment indicates $95 \% \mathrm{Cl}$. The $\mathrm{x}$-axis is transformed on $\log _{10} \mathrm{scale}^{6}$.

Ordinal logistic regression model results show that Career Stage, OS Attitude and OS Barrier were significant predictors of OS Practice. Regarding Career Stage (Years After PhD), for every year of increase in years after $\mathrm{PhD}$, the odds of engaging more in OS practices (Sharing Both or Sharing Preprints or Data versus Sharing Neither) increases $8 \%$, holding constant all other variables. This could be interpreted as a result of the sample being composed of OSinterested researchers, where more research experience (i.e., research portfolio) had a more straightforward relationship with engagement in OS.

Regarding OS Attitude, for every unit of increase in attitude to sharing data, the odds of engaging more in OS practices increases $72 \%$, holding constant all other variables. It is promising to see that positive attitudes towards sharing data did translate into some engagement in OS. Considering the more pronounced complexity involved with sharing data (e.g., fear of judgement or criticism, ethical issues, time or skills required for documentations), it makes sense that a positive attitude towards data sharing would be the factor that had the strongest relationship with OS practices among all attitudinal measures.

Regarding OS Barrier, for researchers who reported insecurity as a barrier, the odds of engaging more in OS practices is 0.14 times that of those who did not, holding constant all other variables. In other words, for researchers who did not report insecurity as a barrier, the odds of engaging more in OS practices is 7.14 times (i.e., 1/0.14) that of those who did,

\footnotetext{
${ }^{6}$ Odds ratio is more appropriately plotted on a log scale: The distance between 0.5 and 1 should be the same distance as between 1 and 2 since both are a doubling of the odds, for example.
} 
holding constant all other variables (positive odds ratio) ${ }^{7}$. Similarly, for those who did not report practicality as a barrier, the odds of engaging more in OS practices is 4 times that of those who did. Interestingly, for those who did not report additional barriers (which includes those who expressed any of the other four barriers), the odds of engaging more in OS practice is 4.55 times that of those who did. It is worth noting that compared with positive attitudes, the effect sizes of the barrier measures are much larger, which suggests that removing barriers might be a more effective and imperative task than cultivating positive attitudes. Considering that the respondents were already OS-interested, it is plausible that those who care less about OS may be further deterred by perceived barriers.

\section{Discussion}

Overall, respondents to this survey showed positive attitudes towards OS. This could be due in part to the self-selective nature of the sample (as participants were free to decide whether to take part or not). While we expect that researchers who object to OS would have made the time to express their views, it is likely that others in our target population with no opinion or no interest in OS chose not to respond. A more representative survey would need to provide a simple method of opting out. It would also need to adopt a diversification strategy to reach a more representative sample of researchers (across countries, languages, research orientations, and so forth).

In spite of these limitations, we believe this preliminary survey has revealed some interesting findings, which we discuss below.

\subsection{OS in AL: momentum on the rise}

The overall OS attitudes in this sample were positive, which echoes what was found in the survey by Marsden, Thompson and LaFlair in 2018 (cited in Marsden, 2019) where the majority of respondents believed open research materials and data were very beneficial to $\mathrm{AL}$ and is in line with the positive attitudes towards replication studies in the survey by McManus (2021). This finding also broadly aligns with what was found in an interdisciplinary study by Christensen and colleagues (2020), which surveyed researchers in economics, political science, psychology and sociology. Specifically, attitudes between PhD students and published authors were "remarkably similar" (Christensen et al., 2020, p. 21).

Nonetheless, our survey revealed more nuanced patterns: PhD students had the most positive attitudes (especially towards sharing data), strongest self-efficacy in open practice and technical skills (e.g., using R), and high willingness to engage in open practices in the future, even though they only had limited engagement with OS practices. Senior researchers, in contrast, engaged more with preprint and data sharing and had largely positive OS attitudes (though similar to or less positive than PhD students). Bearing the limit of our sample in mind, the findings suggest a promising future for $O S$ in $A L$, where the youngest generation of applied linguists, currently least engaged in sharing preprints and data, is actually building up the momentum to embrace OS. The high prevalence of $\mathrm{R}$ use in $\mathrm{PhD}$ students suggests that younger researchers are equipped with the technical know-how and their engagement with open practices may just be a matter of time, as expressed in the open-ended answers in the survey as well (Table 2, Table 3).

\subsection{Top-down drivers of change: incentives}

\footnotetext{
${ }^{7}$ Odds ratio less than one is less straightforward to interpret than its counterpart (i.e., OR $>1$ ). Interested readers may refer to https://stats.idre.ucla.edu/r/dae/ordinal-logistic-regression/ for an accessible introduction of ordinal logistic regression using $\mathrm{R}$.
} 
Despite the positive signals observed in the data, the substantial barriers to OS should not be taken lightly. Our regression model results showed much larger effect sizes associated with OS barriers than those associated with OS attitudes. This means that addressing the barriers and concerns, be it psychological, practical, or epistemological, may be more effective in increasing the engagement in OS than cultivating positive attitudes towards OS. The fact that insecurity (e.g., fear of criticism), practicality (e.g., lack of time) and other concerns (e.g., research paradigm differences) were substantial deterrents to OS practices, even with a sample generally positive towards OS, points to more profound issues.

The vulnerability associated with sharing data and preprints is not as straightforward as something entirely dependent on the individual researchers but rather, intertwined with issues of incentives and norms of the research community. While junior researchers may be more vulnerable to insecurity (e.g., fear of jeopardising review, fear of others mining the data), for senior researchers who enjoyed more security in employment, "having no time" appeared to be another barrier (Figure 14, Figure 15). Taken together, a common denominator seems to be the misalignment between existing incentives (e.g., how research and researchers are evaluated) on one side and core OS values on the other. Take sharing data as an example: When the current system rewards researchers who can publish a large number of papers within a short time, researchers who commit long hours to properly document and prepare the data and code for sharing could be taking a penalty. In this sense, what is good for science is not necessarily good for the scientist (Orben, 2021).

There have been some efforts to address this misalignment. For instance, Journal of Child Language started requiring full information about methods and study materials during the review process from 2018 and Language Learning did so from 2020. Applied Psycholinguistics has been requiring the analysis code and data (in addition to research materials) to be openly available since January 2022. Recently, Studies in Second Language Acquisition launched a call for proposals for a special issue of close and approximate replication studies to be published in 2024. Granted, journal policies that promote openness and transparency play an important role in shifting the norm of the research community, but journals should not be the only catalyst of change. Universities, funding agencies (see Brysbaert, this volume), research methods courses (see Campbell \& Koessler, this volume), professional societies and institutions all have a role to play in establishing better research evaluation criteria to build a healthier research ecosystem where the interests of $A L$ and $A L$ researchers are better aligned. The Declaration on Research Assessment (DORA; http://sfdora.org) is one such top-down approach, with the aim to improve how research is evaluated for decisions that impact research careers. In addition, there have also been innovative efforts to explore more diversified forms of research outputs and ways of scholarly communication. For instance, Octopus (https://science-octopus.org/) is platform that supports eight types of publication from research hypothesis to peer review. This innovative model is free, fast and meritocratic, which aims to positively disrupt the existing publishing model and promote open and transparent research.

\subsection{Bottom-up drivers of change: OS communities}

In addition to the top-down drivers of change such as incentives, bottom-up efforts to raise the awareness of and promote the practice of OS are also needed. Recall in the survey there were many participants who reported not knowing how to share preprints or data (Figure 13, Figure 15). This, in conjunction with the generally positive attitudes observed in the data, suggests that the provision of teaching and training of OS practices is likely to result in greater engagement in OS practices (cf. Isbell et al., 2022). 
The next question in line is how do we integrate OS principles and practices into the teaching and training of applied linguists? More importantly, how do we achieve such purposes without overburdening the individual researchers and trainers who already shoulder heavy workloads? Communities aiming to support and promote OS serve as a practical solution and help foster a culture of OS from the bottom up (Azevedo et al., 2022). For instance, there are initiatives with a focus on open pedagogy and open educational resources to incorporate OS into undergraduate and graduate programmes not only in psychology (e.g., Chopik et al., 2018; Pownall et al., 2021) but also interdisciplinary (e.g., FORRT, 2019). Through crowd-sourcing efforts in OS communities (Azevedo et al., 2022), ready-to-use teaching materials such as lesson plans (Pownall et al., 2021) and glossaries (Parsons et al., 2022) can be used by any educator or student, regardless of the level of OS in the local curriculum. Within AL, there have also been efforts by researchers at the university level (Bolibaugh et al., 2020), which serves as a foundation for wider collaborations beyond the institutional and geographical boundaries. It is also worth noting that a new AILA research network (Open Applied Linguistics; https://openappliedlinguistics.org/) dedicated to the promotion of open scholarship was founded in February 2022. Its first network event is a two-day online symposium on open scholarship in AL to be held in June 2022, with speakers from within and outside AL to discuss topics ranging from replication and registered report to qualitative research and publisher perspectives. While OS is still an emerging topic and OS practices are not yet the norm in AL, these initiatives can be taken as promising steps to spark wider discussions in the AL community and ultimately contribute to a more open, transparent, and sustainable future for AL.

\section{Conclusion}

In this chapter we presented a preliminary survey on applied linguists' perception and practice of OS as well as the perceived barriers to OS. On one hand, our results confirm that at least for quantitative researchers, there is a general consensus on the value and relevance of OS to the AL community ( $c f$. Isbell et al., 2022; McManus, 2021). On the other hand, our results also reveal the many barriers and issues waiting to be resolved. While there are topdown and bottom-up initiatives advancing the field towards a more open future, it is important to highlight that we do not believe OS to be a fixed or uniform construct, which means that OS initiatives cannot be implemented with such assumptions either. AL comprises a wide range of methodologies and epistemological perspectives and not all values of OS are transposable across approaches. A universal OS prescription may not be achievable, or indeed desirable. Open discussions bringing together researchers with diverse epistemological stances will be necessary to collectively define optimal OS practices across research paradigms in AL. It is hoped that our chapter could serve as a prompt for rethinking and reappraising how we do research as applied linguists, what we value as pillars of $A L$ and what we can do to foster a culture that upholds the values we hold dear.

\section{References}

Azevedo, F., Liu, M., Pennington, C. R., Pownall, M., Evans, T. R., Parsons, S., Elsherif, M. M., Micheli, L., Westwood, S. J., \& Framework for Open, Reproducible Research Training

(FORRT). (2022). Towards a culture of open scholarship: The role of pedagogical 
communities. BMC Research Notes, 15(1), 75. https://doi.org/10.1186/s13104-02205944-1

Bolibaugh, C., Marsden, E., Vanek, N., \& Asbury, K. (2020). Education Researchers for Open Science (EROS) at the University of York. osf.io/qwurf

Chopik, W. J., Bremner, R. H., Defever, A. M., \& Keller, V. N. (2018). How (and Whether) to Teach Undergraduates About the Replication Crisis in Psychological Science. Teaching of Psychology, 45(2), 158-163. https://doi.org/10.1177/0098628318762900

Christensen, G., Wang, Z., Paluck, E. L., Swanson, N., Birke, D. J., Miguel, E., \& Littman, R. (2020). Open science practices are on the rise: The state of social science (3s) survey [Preprint]. MetaArXiv. https://doi.org/10.31222/osf.io/5rksu

FORRT. (2019). Introducing a Framework for Open and Reproducible Research Training (FORRT). OSF Preprints. https://doi.org/10.31219/osf.io/bnh7p

Gass, S., Loewen, S., \& Plonsky, L. (2021). Coming of age: The past, present, and future of quantitative SLA research. Language Teaching, 54(2), 245-258.

Isbell, D. R., Brown, D., Chen, M., Derrick, D. J., Ghanem, R., Arvizu, M. N. G., Schnur, E., Zhang, M., \& Plonsky, L. (2022). Misconduct and Questionable Research Practices: The Ethics of Quantitative Data Handling and Reporting in Applied Linguistics. The Modern Language Journal, 106(1), 172-195. https://doi.org/10.1111/modl.12760

Marsden, E. (2019). Open Science and Applied Linguistics: Where are we, and where are we heading? 2019 conference of the American Association for Applied Linguistics (AAAL).

Marsden, E., Alferink, I., Andringa, S., Bolibaugh, C., Collins, L., Jackson, C., Kasprowicz, R., O’Reilly, D., \& Plonsky, L. (2018). Open Accessible Summaries in Language Studies (OASIS) [Database]. https://www.oasis-database.org 
Marsden, E., Mackey, A., \& Plonsky, L. (2016). The IRIS repository of instruments for research into second languages: Advancing methodology and practice. In A. Mackey \& E. Marsden (Eds.), Advancing methodology and practice: The IRIS Repository of Instruments for Research into Second Languages (pp. 1-21). Routledge.

Marsden, E., Morgan-Short, K., Trofimovich, P., \& Ellis, N. C. (2018). Introducing registered reports at language learning: Promoting transparency, replication, and a synthetic ethic in the language sciences. Language Learning, 68(2), 309-320. https://doi.org/10.1111/lang.12284

McManus, K. (2021). Are replication studies infrequent because of negative attitudes? Insights from a survey of attitudes and practices in second language research. Studies in Second Language Acquisition, 1-14. https://doi.org/10.1017/S0272263121000838

Orben, A. (2021). Psychology as a Robust Science-Slides. https://doi.org/10.17605/OSF.IO/XAY92

Parsons, S., Azevedo, F., Elsherif, M. M., Guay, S., Shahim, O. N., Govaart, G. H., Norris, E., O'mahony, A., Parker, A. J., \& Todorovic, A. (2022). A community-sourced glossary of open scholarship terms. Nature Human Behaviour, 6(3), 312-318.

Plonsky, L. (2014). Study quality in quantitative L2 research (1990-2010): A methodological synthesis and call for reform. The Modern Language Journal, 98(1), 450-470.

Plonsky, L., Marsden, E., Crowther, D., Gass, S. M., \& Spinner, P. (2020). A methodological synthesis and meta-analysis of judgment tasks in second language research. Second Language Research, 36(4), 583-621.

Pownall, M., Azevedo, F., Aldoh, A., Elsherif, M., Vasilev, M., Pennington, C. R., Robertson, O., Tromp, M. V., Liu, M., Makel, M. C., Tonge, N., Moreau, D., Horry, R., Shaw, J., Tzavella, L., McGarrigle, R., Talbot, C., Parsons, S., \& FORRT. (2021). Embedding open and reproducible science into teaching: A bank of lesson plans and resources. 
Scholarship of Teaching and Learning in Psychology.

https://doi.org/10.1037/st10000307 